\title{
Tubulocystic Carcinoma of the Kidney: An Evolving Entity
}

\section{Kaushik $\mathbf{M}^{1 *}$, Singh $\mathrm{H}^{2}$ and Mittal $\mathbf{V}^{2}$}

${ }^{1}$ Department of Surgery, Providence Hospital \& Medical Centers, USA

${ }^{2}$ Department of Internal Medicine, St. Vincent's Hospital, USA

\section{Editorial}

Tubulocystic carcinoma remain to be a indolent group of Renal cell carcinomas with highly specific microscopic and immunehistochemical characteristics. Prevalent in the fifth and sixth decade of life, associated with a strong male predominance and exists in a ratio of $7: 1$ in comparison to the female population $[1,2]$. It was not described as a formal entity till 2004 and less than a hundred cases have been diagnosed worldwide [1]. However, over the years the understanding of this pathology has evolved and still undergoing a dynamic change with time. Our aim is to understand the latest advancements and contributions in the evolving understanding of Tubulocystic carcinoma of the kidney since our publication regarding the same in 2014 [1].

Tubulocystic carcinoma of the kidney (TCCK) was initially described as a low grade collecting duct neoplasm by Masson [3]. However, the recent advancements have shown that this carcinoma is a distinct entity. Interestingly, after the development of molecular clustering it was found that these lesions closely resemble papillary variant of renal cell carcinoma [4] presenting as a solitary lesion, although multifocal examples have been seen presenting with variable sizes ranging from 0.3 to $17 \mathrm{~cm}$, with a mean size of $4 \mathrm{~cm}$ [5] and are mostly an incidental finding. The core of this carcinoma is mainly found in the renal cortex but the tumor may also encroach the medulla. TCCK are well circumscribed, uncapsulated neoplasms and the cut surface displays a spongy, bubble wrap like appearance or swiss cheese like structure.

Histological appearance of TCCK is composed of an array of tubules and cysts separated by a thin fibrous septa lined by cuboidal epithelium [6], but recent literature has been focusing more on the genetic and immune-histochemical nature of TCCK. A recent study conducted with 12 cases of Renal Tubulocystic carcinomas using fluorescent in situ hybridization assessment of chromosome number for chromosomes 7 and 17, and for TFE3 translocation supported the fact that Tubulocystic carcinoma of the kidney is a separate entity with an indolent course and may display favorable prognosis [7]. The biological nature of this condition has still not been established. Previous reports have shown that only 6 patients developed metastatic disease [2,8-10] even though TCCK is reported to have a favorable prognosis and usually confined to the renal architecture, 2 out of 6 patients developed distant site metastasis to the bone and liver [9]. TCCK are generally less than 2 $\mathrm{cm}$ at presentation and the patients may present with symptoms of dull aching abdominal pain with or without distension and hematuria [2]. Immunohistochemically, TCCK are found to be reactive to proximal convulated tubule markers like CD10, AMACR, CK8, CK18 and CK 19 [6] as well as PAX2, Kidney specific cadherin, carbonic anhydrase IX, and parvalbumin in some cases [10]. In an effort to differentiate TCCK from papillary RCC Tran et al. studied the immunohistochemistry of 12 cases of TCCK which revealed all to be non- reactive with antibodies against p63 and cytokeratin 20 [11]. Conversely the antibody against AMACR gave a positive reaction in the neoplastic cells, four tumors showed focal labelling with antibody against carbonic anhydrase IX and five tumors displayed a positive reaction against cytokeratin 7 . They did not appreciate any recurrence or metastatic disease with the limited follow up dataset.
Yang et al. performed a Gene expression microarray study to delineate the micro-molecular structure of TCCK when compared to other renal carcinomas as well as to the normal renal architecture [8]. According to them the karyotypic changes in papillary renal cell carcinoma are trisomy of chromosome 17 and 7 with loss of Y chromosome whereas TCCK displayed a gain of chromosome 17 only thereby suggesting a similar genetic nature of Papillary renal cell ca and TCCK. An elevated mRNA level of TP53 was noted, whereas the mRNA levels of FLT1 and CFOS were reduced in TCCK samples. On the contrary, the gene expression profiling performed by Amin, et al. did not overlap the findings of TCCK and papillary RCC and showed an overexpression of amino acid metabolism and cell cycle genes and an under-expression of biopolymer metabolism genes [6]. The difference in the findings can be attributed to the difference in the specimens examined, formalin fixed vs. frozen tissue [11].

More recent evidence has suggested that TCCK with focal dedifferentiation may be a representation of Hereditary leiomyomatosis Renal cell ca syndrome associated Renal cell ca, as a small amount of cases have shown a loss of fumarate hydratase immune-expression and 2-succinocystiene immune-positivity [12]. It has also been seen that TCCK with poorly differentiated foci are indicative of aggressive behavior [13]. One of the two patients in the study by Ming, et al. had metastasis to the pelvic cavity and eventually succumbed to the disease [13]. Both the patients were found to have poorly differentiated areas consisting of collecting duct like carcinomas with marked nuclear atypia and evidence of prominent nucleoli occupying less than $20 \%$ of the tumor mass.

TCCK have also been confused with various other differentials with multilocular appearance such as multilocular cystic renal cell ca, cystic nephroma, mixed epithelial and stromal tumors, cystic oncocytoma, and XP11.2 RCC [14] but the immunohistological and molecular findings make TCCK a distinct and a unique entity. However, making a diagnosis on basis of imaging modalities can be concerning. Ct scan is considered to be a gold standard to differentiate a renal mass, but TCCK can appear as a Bosniak type II to type IV, even if it has solid components. Oderda, et al. described in their case report how a TCCK was initially diagnosed as a renal cyst on CT scan and the patient eventually underwent a radical nephrectomy displaying a large, solid neoplasm on pathology [15]. Hence TCCK can be can be misdiagnosed frequently as cystic lesions or other benign/malignant entities.

*Corresponding author: Manu Kaushik, MD, Department of Surgery, Providence Hospital and Medical Center, Southfield, Michigan, USA, E-mail: manukaushik88@gmail.com

Received February 02, 2016; Accepted February 17, 2016; Published February 29, 2016

Citation: Kaushik M, Singh H, Mittal V (2016) Tubulocystic Carcinoma of the Kidney: An Evolving Entity. J Kidney 2: e105. doi: 10.4172/2472-1220.1000e105

Copyright: (c) 2016 Kaushik M, et al. This is an open-access article distributed under the terms of the Creative Commons Attribution License, which permits unrestricted use, distribution, and reproduction in any medium, provided the original author and source are credited. 
Citation: Kaushik M, Singh H, Mittal V (2016) Tubulocystic Carcinoma of the Kidney: An Evolving Entity. J Kidney 2: e105. doi: 10.4172/24721220.1000 e105

Ultrasound can be a useful adjunct to reach a conclusive diagnosis of TCCK.

Despite the high grade cytology and immunohistochemistry, TCCK displays a favorable prognosis as they are usually localized to the kidney at the time of diagnosis. Most cases have been treated with partial or radical nephrectomy, however cases of recurrence and metastasis have been reported in literature. Bhullar, et al. reported a case of a 33-yearold man who had presented with back pain and was diagnosed with multiple bony metastasis and a larger solid- cystic left renal tumor. Decompression of the spine followed by radical nephrectomy was done and the final pathology had revealed tubulocystic carcinoma with sarcomatoid features [16]. In recent studies the role of Sunitinib, a tyrosine kinase inhibitor historically used for management of metastatic papillary and chromophobe RCC and urothelial RCC has shown partial response in patients with TCCK [13].

Tubulocystic carcinoma of the kidney remains to be a fairly new diagnosis, ongoing studies and research have displayed its unique identity and its distinct immuno-histochemical nature when compared to the other renal neoplasms. However there still remains a grey zone regarding the optimal differentiation and management of TCCK. Further research and studies are needed to understand the biology of this neoplasm, delineation of its optimal management and ascertain the prognosis.

\section{References}

1. Bhullar JS, Bindroo S, Varshney N, Mittal V (2014) Tubulocystic Renal Cell Carcinoma. Journal of Kidney Cancer and VHL 1: 56-62.

2. Yang XJ, Zhou M, Hes O, Shen S, Li R, et al. (2008) Tubulocystic carcinoma of the kidney: clinicopathologic and molecular characterization. Am J Surg Pathol 32: $177-187$.

3. Masson P (1970) Human Tumors, Histology, Diagnosis and Technique. Detroit: Wayne State University Press; Tumeurs Humaines 1955.
4. Bhullar JS, Varshney N, Bhullar AK, Mittal VK (2014) A New Type of Renal cancer-Tubulocystic Carcinoma of the Kidney: A review of Literature. Int J Surg Pathol 22: 297-302.

5. Tran T, Jones CL, Williamson SR, Eble JN, Grignon DJ, et al. (2015) Tubulocystic renal cell carcinoma is an entity that is immunohistochemically and genetically distinct from papillary renal cell carcinoma. Histopathology.

6. Amin MB, MacLennan GT, Gputa R, Grignon D, Paraf F, et al. (2009) Tubulocystic carcinoma of the kidney: clinicopathological analysis of 31 cases of a distinctive rare subtype of renal cell carcinoma. Am J Surg Pathol 33: 384 392

7. Srigley JR, Delahunt B (2009) Uncommon and recently described renal carcinomas. Mod Pathol 22: S2-S23.

8. Alexiev BA, Drachenberg CB (2013) Tubulocystic carcinoma of the kidney: a histologic, immunohistochemical, and ultrastructural study. Virchows Arch 462: 575-581.

9. Podduturi V, Adair V, Zhang H (2015) Tubulocystic Carcinoma of the Kidney Proc (Bayl Univ Med Cent) 28: 384-385.

10. Tran T, Jones CL, Williamson SR, Eble JN, Grignon DJ, et al. (2015) Tubulocystic renal cell carcinomais an entity that is immunohistochemically and genetically distinct from papillary renal cell carcinoma. Histopathology

11. Zhou M, Yang XJ, Lopez JI, Shah RB, Hes O, et al. (2009) Renal tubulocystic carcinoma is closely related to papillary renal cell carcinoma: implications for pathological classification. Am J Surg Pathol 33: 1840-1849.

12. Kakkar A, Sharma M, Uppal M, Chumber M (2015) Tubulocystic Renal cell carcinoma: Report of a rare case. Can Urol Assoc J 9: E654-E65.

13. Ming Z, Teng X, Ru G, Zhao Z, Hu Q, et al. (2015) Tubulocystic renal carcinoma with poorly differentiated foci is indicative of aggressive behavior: clinicopathologic study of two cases and review of literature. Int J Clin Exp Pathol 8: 11124-1113.

14. Srigley JR, Delahunt B (2009) Uncommon and recently described renal carcinomas. Mod Pathol 22: S2-S23.

15. Oderda M, Maletta F, Palazzetti A, Faletti R, Falcone M, et al. (2015) Tubulocystic renal cell carcinoma disguised as a renal cyst. Minerva Urol Nefrol.

16. Bhullar JS, Thamboo T, Esuvarnathan K (2011) Unique Case of Tubulocystic Carcinoma of the kidney with Sarcomatoid Feratures: A New Entity. 